\title{
Plasminogen activator inhibitor-1: a risk factor for deep vein thrombosis after total hip arthroplasty
}

\author{
Ju Tang, Wei Zhu, Xiaoliang Mei and Zhenxiang Zhang*
}

\begin{abstract}
Background: The onset of deep vein thrombosis (DVT) in patients after total hip arthroplasty (THA) may expand or enlarge and subsequently lead to significant mortality. The objective of this study was to investigate potential risk factors for DVT in patients after THA.

Methods: Eligible patients with hip joint diseases who were scheduled for unilateral primary THA at our hospital were prospectively included into this study. The demographic and clinical features, preoperative plasma biomarkers were detailed, recorded, and compared. The multiple logistic regression analysis was used to evaluate potential risk factors for DVT.

Results: A total of 214 subjects were enrolled into our study cohort for the final analysis, and 23 of them have suffered DVT with an incidence of 9.5\%. The performance of logistic regression analysis showed that preoperative expression of plasminogen activator inhibitor-1 (PAl-1) was an independent risk factor for the onset of DVT in patients after THA (OR 1.18, 95\% Cl 1.04-1.29; $p=0.011)$
\end{abstract}

Conclusions: Our study indicated preoperative plasma PAI-1 expression as an independent risk factor for DVT in patients who underwent THA.

Keywords: Total hip arthroplasty, Deep vein thrombosis, Plasminogen activator inhibitor-1, Risk factor

\section{Background}

Venous thromboembolism (VTE) is recognized as one of most common complications during patients undergoing total hip arthroplasty (THA) and can be closely related to postoperative mortality with uncertain prophylaxis [1]. Previous studies in western populations have reported the incidence of deep vein thrombosis (DVT) in THA patients can be as high as $40-60 \%$ with no appropriate chemoprophylaxis [2]. Another study in Asian countries has reported the incidence of DVT around $8 \%$, which is significantly lower than western countries [3]. Accurate, rapid diagnosis and valid prediction of DVT during the perioperative period are essential due to its significant impact on morbidity and mortality [4]. Previous studies have established D-dimer

\footnotetext{
* Correspondence: zhangzhenxiangtz@sina.com

Department of Joint Surgery, Taizhou People's Hospital, Medical School of Nantong University, No. 210 Yingchun Road, Taizhou City, Jiangsu Province, 225300, China
}

(c) The Author(s). 2018 Open Access This article is distributed under the terms of the Creative Commons Attribution 4.0 International License (http://creativecommons.org/licenses/by/4.0/, which permits unrestricted use, distribution, and reproduction in any medium, provided you give appropriate credit to the original author(s) and the source, provide a link to the Creative Commons license, and indicate if changes were made. The Creative Commons Public Domain Dedication waiver (http://creativecommons.org/publicdomain/zero/1.0/) applies to the data made available in this article, unless otherwise stated. other study conducted by Thomas et al. did not support the predictive value of D-dimer in symptomatic DVT after total joint arthroplasty [7]. The occurrence of thrombosis can be ascribed to the imbalance between coagulation and fibrinolytic factors [8]. Previous studies have revealed that plasminogen activator inhibitor-1 (PAI-1), a central regulative factor for the fibrinolytic system, has been considered as a critical role in hemostatic clot stabilization and vascular thrombosis determination $[9,10]$. Impaired fibrinolytic function induced by elevated PAI-1 expression is commonly observed in patients with thrombotic disease. Previous reports by Wiman B have indicated preoperatively increased PAI-1 concentration as a potential predicator for postoperative DVT in subjects undergoing hip surgery with poorly understood pathophysiology [11]. Another study conducted in Indian patients has also shown a close association between raised PAI-1 level which is 
regulated by PAI-1 gene 4G/5G polymorphism and DVT through a hypoactive fibrinolytic pathway [12]. Reports by Joe et al. have showed the critical role of plasmin in thrombus resolution and the lack of PAI- 1 closely correlates with greater vein wall fibrosis [13]. However, whether PAI-1 can serve as a risk factor for DVT in patients undergoing THA still remains unknown. The purpose of our present study was to investigate potential risk factors for DVT after THA.

\section{Methods}

\section{Patients}

This prospective study protocol was approved by the Medical Institutional Ethics Committee of Taizhou People's Hospital and Jiangsu province. Eligible patients who underwent unilateral primary THA at Taizhou People's Hospital from May 2012 to January 2017 were prospectively enrolled. The written informed consent was obtained from each participant. The exclusion criteria were described as follows: (1) with thromboembolism history; (2) ongoing antiplatelet or anticoagulation treatment for cerebrovascular or cardiac diseases; (3) with revision hip arthroplasty; (4) diagnosed with DVT before the surgery with Doppler ultrasonography. Antiplatelet or anticoagulant medications were discontinued for 1 week prior to surgery.

Antiplatelet or anticoagulant medications (such as low molecular heparin) were also not routinely conducted postoperatively. Elastic stockings wearing and early lower limb function exercise were the only postoperative antithrombotic prophylactic treatments for the enrolled patients until the onset of DVT by Doppler ultrasonography or clinical symptoms.

The demographic characteristics (age, sex, etc.) and preoperative comorbidities (diabetes mellitus, anemia, etc.) from all enrolled patients were noted in details at admission. The operation-related indexes including operation side, American Society of Anesthesiologists (ASA) physical status, etc. were also recorded. DVT in distal and proximal veins was evaluated in each participant on preoperative, postoperative day 7 and day 30 with Doppler ultrasonography. The time from operation to DVT was also noted. The definition of DVT was confirmed according to previous studies [14], "new diagnosis of thrombus or blood clot in the superficial or deep venous system coupled with inflammation or not."

\section{Blood sampling and laboratory examinations}

The preoperative (1 day before the surgery) blood samples were collected from each enrolled patient into tubes containing ethylenediaminetetraacetic acid (EDTA). Then plasma samples were isolated and stored at $-80^{\circ}$ $\mathrm{C}$ for use. The plasma D-dimer, tissue factor (TF), microparticle-tissue factor (MP-TF), and thrombinactivatable fibrinolysis inhibitor (TAFI) (Abcam Co., Cambridge, UK) levels were analyzed by enzymelinked immuno sorbent assay (ELISA). Double antibody enzyme-linked immunosorbent assays were utilized for the measurement of plasma PAI-1 (Abcam Co., Cambridge, UK) concentrations. Plasma expressions of D-dimer were detected by latex agglutination turbidimetry using FIA8000 (Jidan Co., Nanjing, China) with the normal range of $<0.5 \mu \mathrm{g} / \mathrm{mL}$. The preoperative hemocyte analyses including white blood cell (WBC) counts, hemoglobin, hematocrit, and albumin were also conducted. We also measured coagulation function indexes including platelet counts, fibrinogen, prothrombin time (PT), activated partial thromboplastin time (APTT), and prothrombin timeinternational normalized ratio (PT-INR).

\section{Statistical analysis}

SPSS 19.0 software (SPSS Inc., Chicago, IL, USA) and GraphPad prism 5.0 (GraphPad Inc., San Diego, CA, USA). Data were expressed as mean (standard error) or number $(n, \%)$, respectively. Chi-square test or Fisher's exact test was used for the comparison of qualitative data. Mann-Whitney $U$ test or Student's $t$ test was utilized for quantitative data analysis appropriately. Multiple logistic regression analysis was used for the determination of potential risk factors contributed to the presence of DVT. A $p$ value $<0.05$ with bilateral probability was considered statistically significant.

\section{Results}

\section{Demographic and clinical features}

Of the 241 enrolled participants, 27 were excluded from this study: 4 declined to cooperate, 7 information missed, and 16 were ineligible due to the exclusion criteria. The remaining 214 subjects were enrolled into our study cohort for the final analysis, and 23 of them have suffered DVT with an incidence of $9.5 \%$ (5 patients were actually symptomatic). The detailed demographic and descriptive data of this study cohort were exhibited in Table 1. Sixteen of 23 patients with DVT were found early in the postoperative course (day 7), and no signs for pulmonary embolism in our series were observed. Those patients who suffered from DVT had a higher age than those without DVT (66.7 vs 62.6 years, $p=0.018$ ). Differences were found between patients with or without DVT regarding preoperative comorbidities of diabetes mellitus, atrial fibrillation, and coronary artery disease. No statistical difference was found in the comparison of gender, BMI, ASA physical status, operation side, estimated blood loss, infusion volume, and urine volume between these two groups. 
Table 1 Characteristics of patients with or without DVT after THA

\begin{tabular}{|c|c|c|c|}
\hline \multirow[t]{2}{*}{ Parameters } & \multicolumn{2}{|l|}{ DVT } & \multirow[t]{2}{*}{$p$ value } \\
\hline & Yes & No & \\
\hline Number $(n)$ & 23 & 191 & - \\
\hline Age (years) & $66.7 \pm 8.6$ & $62.6 \pm 7.7$ & $0.018^{*}$ \\
\hline \multicolumn{4}{|l|}{$\operatorname{Sex}(n, \%)$} \\
\hline Male & $8(34.8 \%)$ & $70(36.6 \%)$ & \\
\hline Female & $15(65.2 \%)$ & $121(63.4 \%)$ & 0.861 \\
\hline BMI $\left(\mathrm{kg} / \mathrm{m}^{2}\right)$ & $23.7 \pm 3.1$ & $23.5 \pm 3.3$ & 0.783 \\
\hline \multicolumn{4}{|l|}{ Comorbidities } \\
\hline Diabetes mellitus & $7(30.4 \%)$ & $26(13.6 \%)$ & $0.035^{*}$ \\
\hline Anemia & $3(13.0 \%)$ & $20(10.5 \%)$ & 0.565 \\
\hline Atrial fibrillation & $5(21.7 \%)$ & $12(6.3 \%)$ & $0.024^{*}$ \\
\hline Hypertension & $8(34.8 \%)$ & $55(28.8 \%)$ & 0.552 \\
\hline Hyperlipidemia & $3(13.0 \%)$ & $20(10.5 \%)$ & 0.721 \\
\hline Malignancy & $2(8.7 \%)$ & $11(5.8 \%)$ & 0.636 \\
\hline Peripheral artery disease & $1(4.3 \%)$ & $6(3.1 \%)$ & 0.554 \\
\hline Cerebrovascular disease & $2(8.7 \%)$ & 17(8.9\%) & 1.000 \\
\hline Coronary artery disease & $5(21.7 \%)$ & 15(7.9\%) & $0.047^{*}$ \\
\hline \multicolumn{4}{|l|}{ ASA physical status } \\
\hline$|-| \mid$ & $15(65.2 \%)$ & 102(53.4\%) & \\
\hline III-IV & $8(34.8 \%)$ & $89(46.6 \%)$ & 0.282 \\
\hline \multicolumn{4}{|l|}{ Operation side } \\
\hline Left & $10(43.5 \%)$ & 109(57.1\%) & \\
\hline Right & $13(56.5 \%)$ & $82(42.9 \%)$ & 0.215 \\
\hline Duration of surgery (min) & $164.7 \pm 31.3$ & $150.8 \pm 30.1$ & $0.038^{*}$ \\
\hline Estimated blood loss (ml) & $225.7 \pm 167.4$ & $217.4 \pm 145.8$ & 0.800 \\
\hline Infusion volume (mL) & $2188.7 \pm 897.5$ & $2297.1 \pm 974.2$ & 0.612 \\
\hline Urine volume $(\mathrm{mL})$ & $894.7 \pm 427.5$ & $788.5 \pm 511.4$ & 0.340 \\
\hline
\end{tabular}

DVT deep vein thrombosis, THA total hip arthroplasty, ASA American Society of Anesthesiologists, $B M I$ body mass index. $p$ values were calculated by chi-square test, Fisher's exact test, Student's $t$ test, or Mann-Whitney $U$ test ${ }^{*} p$ value $<0.05$

\section{Preoperative biomarkers and DVT}

The impact of preoperative biomarkers including hemocyte routine analysis, coagulation function indexes, plasma expressions of D-dimer, TF, MP-TF, TAFI, and PAI-1 on thrombogenesis was assessed. As shown in Table 2, the significant correlation with DVT was only observed between plasma concentrations of albumin, D-dimer, PAI-1, and TAFI. However, when comparing patients with and without DVT, no significant difference was identified between DVT and WBC count, hemoglobin, hematocrit, platelet count, fibrinogen, PT, APTT, PT-INR, creatinine, TF, or MP-TF.

\section{Risk factors for DVT}

All these nine risk factors mentioned above (Tables 1 and 2) were included into the multivariate logistic
Table 2 Preoperative biomarkers of patients with or without DVT after THA

\begin{tabular}{|c|c|c|c|}
\hline \multirow[t]{2}{*}{ Biomarkers } & \multicolumn{2}{|l|}{ DVT } & \multirow[t]{2}{*}{$p$ value } \\
\hline & Yes & No & \\
\hline Number $(n)$ & 23 & 191 & - \\
\hline WBC count $(\times 10[9] / L)$ & $6.2 \pm 1.3$ & $5.9 \pm 1.6$ & 0.388 \\
\hline Hemoglobin (g/L) & $129.4 \pm 16.5$ & $132.2 \pm 20.1$ & 0.522 \\
\hline Hematocrit (\%) & $40.1 \pm 4.1$ & $40.8 \pm 4.7$ & 0.495 \\
\hline Platelet count $(\times 10[9] / L)$ & $221.1 \pm 48.5$ & $233.4 \pm 64.1$ & 0.375 \\
\hline Fibrinogen (mg/dl) & $354.5 \pm 137.7$ & $338.7 \pm 124.5$ & 0.570 \\
\hline PT(s) & $12.6 \pm 1.9$ & $13.1 \pm 2.2$ & 0.298 \\
\hline APTT(s) & $30.4 \pm 3.5$ & $30.1 \pm 4.4$ & 0.753 \\
\hline PT-INR & $0.98 \pm 0.06$ & $0.99 \pm 0.08$ & 0.563 \\
\hline Albumin $(\mathrm{g} / \mathrm{L})$ & $37.1 \pm 5.1$ & $39.3 \pm 4.8$ & $0.040^{*}$ \\
\hline Creatinine $(\mu \mathrm{mol} / \mathrm{L})$ & $69.5 \pm 25.1$ & $61.1 \pm 20.7$ & 0.074 \\
\hline D-dimer $(\mu \mathrm{g} / \mathrm{mL})$ & $2.5 \pm 1.9$ & $1.7 \pm 1.2$ & $0.005^{*}$ \\
\hline TF $(p g / m L)$ & $24.4 \pm 12.4$ & $28.3 \pm 14.4$ & 0.215 \\
\hline MP-TF (pg/mL) & $0.51 \pm 0.19$ & $0.46 \pm 0.23$ & 0.318 \\
\hline PAl-1 (ng/mL) & $43.1 \pm 18.7$ & $32.1 \pm 12.5$ & $<0.001^{*}$ \\
\hline TAFI (\%) & $133.5 \pm 30.1$ & $147.4 \pm 28.7$ & $0.030^{*}$ \\
\hline
\end{tabular}

DVT deep vein thrombosis, THA total hip arthroplasty, WBC white blood cell, PT prothrombin time, APTT activated partial thromboplastin time, PT-INR prothrombin time-international normalized ratio, TF tissue factor, MP-TF microparticle-tissue factor, PAI-1 plasminogen activator inhibitor-1, TAFI thrombin-activatable fibrinolysis inhibitor. $p$ values were calculated by Student's $t$ test or Mann-Whitney $U$ test

${ }^{*} p$ value $<0.05$

regression analysis. As shown in Table 3, the performance of logistic regression analysis showed that preoperative expression of PAI-1 was an independent risk factor for the onset of DVT in patients after THA (OR 1.18, 95\% CI 1.04-1.29; $p=0.011$ ).

Table 3 Multiple logistic regression analysis for DVT in patients after THA

\begin{tabular}{llll}
\hline Risk factors & \multicolumn{3}{l}{ Multiple logistic regression } \\
\cline { 2 - 4 } & OR & $95 \% \mathrm{Cl}$ & $p$ value \\
\hline Age (years) & 5.12 & $0.54-10.32$ & 0.241 \\
Diabetes mellitus & 0.94 & $0.89-1.16$ & 0.413 \\
Atrial fibrillation & 1.08 & $0.84-1.32$ & 0.368 \\
Coronary artery disease & 0.91 & $0.71-1.25$ & 0.587 \\
Duration of surgery & 1.22 & $0.61-2.21$ & 0.612 \\
Albumin & 1.57 & $0.97-2.51$ & 0.063 \\
D-dimer & 1.02 & $0.62-1.59$ & 0.235 \\
PAl-1 & 1.18 & $1.04-1.29$ & $0.011^{*}$ \\
TAFI & 1.41 & $0.81-2.47$ & 0.207 \\
\hline
\end{tabular}

DVT deep vein thrombosis, THA total hip arthroplasty, PAI-1 plasminogen activator inhibitor-1, TAFI thrombin-activatable fibrinolysis inhibitor, $\mathrm{Cl}$ confidence interval, $O R$ odds ratio

${ }^{*} p$ value $<0.05$ 


\section{Discussion}

The onset of DVT in patients after THA may expand or enlarge, and subsequently lead to pulmonary thromboembolism, a critical postoperative complication related to significant mortality [15]. Therefore, early diagnosis and predication of DVT is of great importance in patients undergoing THA, especially taking the limitations of current diagnostic tools into consideration. Although previous literature has established the incidence and risk factors of DVT after primary THA, a lack of consensus has been conducted [16]. Our results have indicated an incidence of $9.5 \%$ for DVT after unilateral primary THA, which was relatively higher than previous reports $[3,17]$. We considered that the different races, ages, and inclusion criteria might lead to the different results. Moreover, the reported DVT prevalence might be overwhelmingly under-reported without postoperative routine ultrasound screening. The most significant finding of our present study was that PAI-1 was an independent risk factor for postoperative DVT after THA instead of D-dimer. Several previous studies have reported the predicative value of D-dimer for DVT after THA [18], which was not quite in accordance with our results. Moreover, a study containing 295 consecutive medical patients has also showed some routine blood tests (C-reactive protein, erythrocyte sedimentation rate, Ddimer, etc.) as risk factors for DVT [19]. Many existed confounding factors (advanced age, preoperative comorbidities, anesthesia projects, etc.) could be significantly associated with the conclusions [20, 21]. We considered that the different races, age ranges, cohort characteristics, preoperative comorbidities, inclusion criteria, and antithrombotic prophylactic treatments around the surgery could all be potential explanations for our different conclusions with some other reports.

As reported by previous literature, urokinase plasminogen activator (uPA) and tissue-type plasminogen activator (tPA) play critical actions in the primary mediation of intravascular fibrinolysis [22]. PAI-1 can modulate the plasminogen activation system by forming irreversible inhibitory complexes combining with uPA and tPA [23]. Previous studies have indicated the critical role of PAI-1 in hemostatic clot stabilization due to the close association between PAI-1 deficiency and abnormal bleeding [24]. Furthermore, elevated plasma expression of PAI-1 has been revealed as a significant risk factor for myocardial infarction [25] and DVT [26] by inhibiting endogenous fibrinolysis, which is consistent with our results. However, studies about correlations between PAI-1 concentrations and the maintenance of occlusive thrombosis still remain controversial. A study conducted in murine has reported no obvious correlation observed between time to thrombosis and PAI-1 deficiency [27]. Another study in mice of pulmonary embolism model has established that accelerated lysis of thrombus was associated with PAI-1 deficiency [28]. Important role of PAI-1 and vitronectin was also indicated in the vascular injury-associated occlusive thrombosis by regulating endogenous fibrinolysis [8]. Results from a large population-based prospective study by Folsom AR et al. failed to show a positive association between PAI-1 expression and risk of venous thrombosis [29]. In contrast, several other studies have offered evidence that postoperative thrombosis was associated with increased plasma PAI-1 expressions [30], which was in agreement with our results. PAI- 1 , derived from endothelial or platelet, is normally complexed to vitronectin and serves as an efficient inhibitor of thrombin, and activated protein $C$. pai-1 can modulate the activity of fibrinolytic system by competing with thrombomodulin and in combination with activated protein $\mathrm{C}$ inhibition [31].

\section{Conclusion}

In conclusion, our study indicated preoperative plasma PAI-1 expression as an independent risk factor for DVT in patients after THA. More careful evaluation and aggressive anticoagulation were recommended to prevent postoperative DVT for those patients with elevated PAI-1 levels. In addition, further multi-center and large-scale studies are still required to verify the effectiveness of risk stratification for DVT following THA.

\section{Abbreviations \\ APTT: Activated partial thromboplastin time; ASA: American Society of Anesthesiologists; DVT: Deep vein thrombosis; \\ EDTA: Ethylenediaminetetraacetic acid; ELISA: Enzyme-linked immuno sorbent assay; MP-TF: Microparticle-tissue factor; PT: Prothrombin time; PT- INR: Prothrombin time-international normalized ratio; TAFI: Thrombin- activatable fibrinolysis inhibitor; TF: Tissue factor; THA: Total hip arthroplasty; VTE: Venous thromboembolism}

\section{Acknowledgements \\ None. \\ Funding \\ None. \\ Availability of data and materials \\ Please email to the author for the data and materials. \\ Authors' contributions \\ JT and WZ participated in the conception and design, data collection, statistical analysis, and wrote the manuscript. XLM and ZXZ participated in the conception and design and data collection. All of the authors have read and approved the final manuscript.}

\section{Ethics approval and consent to participate}

This prospective study protocol was approved by the Medical Institutional Ethics Committee of Taizhou People's Hospital and Jiangsu Province. The written informed consent was obtained from each participant.

Consent for publication

Not applicable.

Competing interests

The authors declare that they have no competing interests. 


\section{Publisher's Note}

Springer Nature remains neutral with regard to jurisdictional claims in published maps and institutional affiliations.

Received: 15 October 2017 Accepted: 2 January 2018

Published online: 10 January 2018

\section{References}

1. Dua A, Desai SS, Lee CJ, Heller JA. National trends in deep vein thrombosis following total knee and total hip replacement in the United States. Ann Vasc Surg. 2017;38:310-4

2. Geerts WH, Bergqvist D, Pineo GF, Heit JA, Samama CM, Lassen MR, et al. Prevention of venous thromboembolism: American College of Chest Physicians Evidence-Based Clinical Practice Guidelines (8th edition). Chest. 2008;133(6 Suppl):381S-453S.

3. Wong KL, Daguman R, Lim K, Shen L, Lingaraj K. Incidence of deep vein thrombosis following total hip arthroplasty: a Doppler ultrasonographic study. J Orthop Surg (Hong Kong). 2011;19(1):50-3.

4. Yamaguchi T, Hasegawa M, Niimi R, Sudo A. Incidence and time course of asymptomatic deep vein thrombosis with fondaparinux in patients undergoing total joint arthroplasty. Thromb Res. 2010;126(4):e323-6.

5. Sudo A, Wada H, Nobori T, Yamada N, Ito M, Niimi R, et al. Cut-off values of D-dimer and soluble fibrin for prediction of deep vein thrombosis after orthopaedic surgery. Int J Hematol. 2009:89(5):572-6.

6. Cosmi B, Palareti G. Update on the predictive value of D-dimer in patients with idiopathic venous thromboembolism. Thromb Res. 2010; 125(Suppl 2):S62-5.

7. An TJ, Engstrom SM, Oelsner WK, Benvenuti MA, Polkowski GG, Schoenecker $J G$. Elevated d-Dimer is not predictive of symptomatic deep venous thrombosis after total joint Arthroplasty. J Arthroplast. 2016;31(10):2269-72.

8. Eitzman DT, Westrick RJ, Nabel EG, Ginsburg D. Plasminogen activator inhibitor-1 and vitronectin promote vascular thrombosis in mice. Blood. 2000;95(2):577-80

9. Fay WP, Shapiro AD, Shih JL, Schleef RR, Ginsburg D. Brief report: complete deficiency of plasminogen-activator inhibitor type 1 due to a frame-shift mutation. N Engl J Med. 1992;327(24):1729-33.

10. Dieval J, Nguyen G, Gross S, Delobel J, Kruithof EK. A lifelong bleeding disorder associated with a deficiency of plasminogen activator inhibitor type 1. Blood. 1991;77(3):528-32.

11. Wiman B. Plasminogen activator inhibitor 1 (PAl-1) in plasma: its role in thrombotic disease. Thromb Haemost. 1995:74(1):71-6.

12. Akhter MS, Biswas A, Ranjan R, Meena A, Yadav BK, Sharma A, et al. Plasminogen activator inhibitor-1 (PAl-1) gene $4 \mathrm{G} / 5 \mathrm{G}$ promoter polymorphism is seen in higher frequency in the Indian patients with deep vein thrombosis. Clin Appl Thromb Hemost. 2010;16(2):184-8.

13. Baldwin JF, Sood V, Elfline MA, Luke CE, Dewyer NA, Diaz JA, et al. The role of urokinase plasminogen activator and plasmin activator inhibitor-1 on vein wall remodeling in experimental deep vein thrombosis. J Vasc Surg. 2012;56(4):1089-97.

14. Sebastian AS, Currier BL, Kakar S, Nguyen EC, Wagie AE, Habermann ES, et al. Risk factors for venous thromboembolism following thoracolumbar surgery: analysis of 43,777 patients from the American College of Surgeons National Surgical Quality Improvement Program 2005 to 2012. Global Spine J. 2016:6(8):738-43.

15. Sasaki S, Miyakoshi N, Matsuura H, Saitoh H, Kudoh D, Shimada Y. Prospective randomized controlled trial on the effect of fondaparinux sodium for prevention of venous thromboembolism after hip fracture surgery. J Orthop Sci. 2009;14(5):491-6.

16. Nam D, Nunley RM, Johnson SR, Keeney JA, Clohisy JC, Barrack RL. Thromboembolism prophylaxis in hip Arthroplasty: routine and high risk patients. J Arthroplast. 2015;30(12):2299-303.

17. Imai N, Miyasaka D, Shimada H, Suda K, Ito T, Endo N. Usefulness of a novel method for the screening of deep vein thrombosis by using a combined Ddimer- and age-based index before total hip arthroplasty. PLoS One. 2017; 12(2):e0172849.

18. Shimoyama Y, Sawai T, Tatsumi S, Nakahira J, Oka M, Nakajima M, et al. Perioperative risk factors for deep vein thrombosis after total hip arthroplasty or total knee arthroplasty. J Clin Anesth. 2012;24(7):531-6.

19. Signorelli SS, Valerio F, Davide C, Oliveri Conti G, Maria F, Ignazio M, et al. Evaluating the potential of routine blood tests to identify the risk of deep vein thrombosis: a 1-year monocenter cohort study. Angiology. 2017:68(7):592-7.

20. Nakamura M, Kamei M, Bito S, Migita K, Miyata S, Kumagai K, et al. Spinal anesthesia increases the risk of venous thromboembolism in total arthroplasty: secondary analysis of a J-PSVT cohort study on anesthesia. Medicine (Baltimore). 2017;96(18):e6748.

21. Wakabayashi H, Hasegawa M, Niimi R, Sudo A. Clinical analysis of preoperative deep vein thrombosis risk factors in patients undergoing total hip arthroplasty. Thromb Res. 2015;136(5):855-8.

22. Collen D, Lijnen HR. Basic and clinical aspects of fibrinolysis and thrombolysis. Blood. 1991;78(12):3114-24.

23. Loskutoff DJ, Sawdey M, Mimuro J. Type 1 plasminogen activator inhibitor. Prog Hemost Thromb. 1989:9:87-115.

24. Schleef RR, Higgins DL, Pillemer E, Levitt LJ. Bleeding diathesis due to decreased functional activity of type 1 plasminogen activator inhibitor. J Clin Invest. 1989;83(5):1747-52.

25. Hamsten A, Wiman B, de Faire U, Blomback M. Increased plasma levels of a rapid inhibitor of tissue plasminogen activator in young survivors of myocardial infarction. N Engl J Med. 1985;313(25):1557-63.

26. Wiman B, Hamsten A. The fibrinolytic enzyme system and its role in the etiology of thromboembolic disease. Semin Thromb Hemost. 1990;16(3): 207-16.

27. Farrehi PM, Ozaki CK, Carmeliet P, Fay WP. Regulation of arterial thrombolysis by plasminogen activator inhibitor-1 in mice. Circulation. 1998; 97(10):1002-8

28. Carmeliet P, Kieckens L, Schoonjans L, Ream B, van Nuffelen A, Prendergast $\mathrm{G}$, et al. Plasminogen activator inhibitor-1 gene-deficient mice. I. Generation by homologous recombination and characterization. J Clin Invest. 1993; 92(6):2746-55.

29. Folsom AR, Cushman M, Heckbert SR, Rosamond WD, Aleksic N. Prospective study of fibrinolytic markers and venous thromboembolism. J Clin Epidemiol. 2003;56(6):598-603.

30. Prins $\mathrm{MH}$, Hirsh J. A critical review of the evidence supporting a relationship between impaired fibrinolytic activity and venous thromboembolism. Arch Intern Med. 1991:151(9):1721-31.

31. Horrevoets AJ. Plasminogen activator inhibitor 1 (PAI-1): in vitro activities and clinical relevance. Br J Haematol. 2004;125(1):12-23.

\section{Submit your next manuscript to BioMed Central and we will help you at every step:}

- We accept pre-submission inquiries

- Our selector tool helps you to find the most relevant journal

- We provide round the clock customer support

- Convenient online submission

- Thorough peer review

- Inclusion in PubMed and all major indexing services

- Maximum visibility for your research

Submit your manuscript at www.biomedcentral.com/submit 